\title{
User Acceptance of Electronic Journals: Interviews with Chemists at Cornell University
}

\section{Linda Stewart}

Full-text electronic journals must be designed effectively if they are to support and promote scholarly activities. This paper presents interview data from chemists who have used an experimental electronic journal system. The first section explores the potential of electronic journals for accomplishing traditional scholarly tasks; the second focuses on the characteristics of an ideal electronic system and its effects on user productivity. Implications for system design are presented. Improvements must be made in the areas of portability, comfort, convenient access, permanence, and serendipity if electronic journals are to gain wide acceptance.

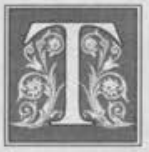

he success of scholarly electronic journals depends on the users' ability to assimilate them into their work habits. The ergonomic implications of electronic text have been reviewed by Andrew Dillon. ${ }^{1}$ The effects of electronic publishing on scholarly communication have been explored by F. W. Lancaster ${ }^{2}$ and Don Schauder. ${ }^{3}$ To describe the interaction between electronic information and the intellectual processes supported by the journal literature, Jan Olsen interviewed forty-six academics who had never previously used electronic journals. ${ }^{4}$ This paper presents interview data related to the potential utility of electronic journals by chemists who have used an experimental system of full-text journals. This information will assist in the effective design of electronic systems so that they will support and promote scholarly activities.

Both libraries and individuals may someday, for economic reasons, need to choose between printed and electronic journals. Moreover, a comparison with printed journals forms a common baseline that users can refer to in describing the potential of electronic journals. In this light, the first part of this paper explores the potential of electronic journals for accomplishing the scholarly tasks traditionally achieved using printed journals. The second part focuses on selected features of an ideal electronic journal system and its potential influence on user productivity.

\section{Methodology}

The data derive from open-ended, hourlong interviews with thirty-nine users of 
the Chemistry Online Retrieval Experiment (CORE) at Cornell University. The CORE system, described in detail by Richard Entlich, 5,6 Michael Lesk, ${ }^{7}$ Larry Krumenaker, ${ }^{8}$ and Stu Borman, ${ }^{9}$ consisted of the full text of twenty American Chemical Society (ACS) journals and the corresponding scanned images of the source journal pages. These were loaded locally at Cornell and made available free to users, twenty-four hours per day, in their offices and certain public buildings. Two different user interfaces were available, one with exact page images and the other with machine-readable text. The responses analyzed in this paper do not

Interviewers were encouraged to make questions open-ended and to probe for more information when appropriate.

deal with the particulars of the CORE system, although, of course, they were influenced by it. Instead, this research was an attempt to persuade users with this defined experience of electronic journal systems to speculate more widely on the genre.

All interviewees were members of the Cornell community who had used the CORE system at least once and who consented to a one-hour personal interview during May and June 1995. Thirteen library staff members conducted the interviews. They scheduled appointments, took notes during interviews, and input the responses on a shared electronic template. The responses were later merged to form a database.

This research project was designed to gather information for the design of electronic journals rather than to test predetermined hypotheses. Survey questions, which were pretested prior to the survey, attempted to elicit not only opinions but also the reasons for them. Interviewers were encouraged to make questions open-ended and to probe for more infor- mation when appropriate. Analysis of nonfactual responses involved grouping together all responses to a particular question, looking for trends within the responses, and coding the responses according to categories generated by the responses themselves.

\section{Characteristics of Participants}

The thirty-nine interviewees included twenty-one graduate students (53.8\%), fourteen holders of doctorates (35.9\%), and four undergraduate students (10.3\%). Doctorates included seven faculty members, one visiting faculty member, three research associates, and three postdoctoral fellows. Thirty-four users were male. Fifty-nine percent were affiliated with the chemistry department, and 10.3 percent each with materials sciences/engineering and food science. The remainder were distributed among a variety of departments. The average number of search sessions per user was 20.6, with a range of 1 to 222 .

\section{Comparison of Electronic Journals with Printed Journals}

\section{System Features Needed for Journal Use}

Olsen, from her interviews with scholars, identified a list of functions that scholars considered essential in an electronic system. ${ }^{10}$ These functions fell into two categories: those that aid in selecting optimal articles and those that facilitate reading them. Activities for selecting the optimal literature include:

- browsing text to support ongoing education and generate new ideas;

- browsing graphics to determine the value of an article;

- flipping pages and scanning;. making physical contact with the material being read;

- experiencing serendipity;

- having a visual overview of a wide body of literature.

Features facilitating reading include:

- physical comfort; 
- adequate type fonts, text design, and layout;

- creation of a print copy;

- portability of the text;

- capability of underlining and annotating.

Interviewees were asked to evaluate the importance of each of the above features. Answers were coded as "very important," "important," and "not important" by the author. Table 1 lists the tasks and features in approximate order of importance to the participants.

All the features except two were considered at least "important" by a majority of users. The single most important feature was the ability to create a printed copy; almost everyone considered it "very important." Four users mentioned the ability to annotate; four others, the ability to preserve materials; two, portability; and two, physical comfort. Printing also allows the comparison of articles and is important for use at the benchtop. One respondent used printing to record the fact that an article had been read.
The ability to browse graphics and text also was of great importance. Users valued browsing graphics for speed and for the fact that a particular discipline may be better expressed graphically. Browsers seek particular structures that are more easily spotted than words within text. Macromolecules may be structurally complex and require color-coding.

Browsing text was important for both generating new ideas and keeping current with related research. The importance of browsing to save time also was suggested by ADONIS users in Great Britain, as described by John Richardson. On 154 occasions $(75.12 \%)$, users looked only at the first page and then made a decision as to printing the article. ${ }^{11}$

Portability of the text, considered by most respondents to refer to portability of the physical copy as opposed to portability of the information, also was considered key. This is understandable within the context of D. J. Pullinger's 1983 investigation, which showed that among potential users of the BLEND electronic text system in the United Kingdom, 65

\section{TABLE 1}

Importance of Tasks and Features to Scholars (by percentage of usable responses)

Task or Feature Very Important Important Not Important

Creation of a print copy

Browsing graphics to determine the value of an article

Browsing text to support ongoing education and generate new ideas

Portability of the text

Flipping pages and scanning

Physical comfort

Adequate type fonts, text design, and layout

Capability of underlining and annotating

Experiencing serendipity

Making physical contact with the material

Having a visual overview of a range of literature

$\begin{array}{lll}80.0 \% & 14.3 \% & 5.7 \% \\ 72.7 & 15.2 & 12.7 \\ 65.8 & 21.1 & 15.2 \\ & & \\ 52.6 & 31.6 & 15.8 \\ 44.7 & 39.5 & 15.8 \\ 36.8 & 44.7 & 18.4 \\ 29.7 & 56.8 & 13.5 \\ & & \\ 40.5 & 32.4 & 27.0 \\ 44.4 & 25.0 & 30.6 \\ 13.5 & 18.9 & 67.6 \\ 8.1 & 27.0 & 64.9 \\ & & \end{array}$


percent of browsing and 85 percent of reading of entire papers took place outside office hours. ${ }^{12}$ Annette Simpson found similar high percentages for twenty academics in a variety of disciplines. ${ }^{13}$ Visual overview of a wide body of literature and physical contact with the article were the two features considered least important by users. Although one interviewee felt that seeing a variety of journals might provoke interest, others mentioned that they already knew which journals they wanted.

A few participants valued physical contact with the article:

\begin{tabular}{|lc|}
\hline \multicolumn{2}{|c|}{ TABLE 2 } \\
$\begin{array}{c}\text { Potential Satisfactory Performance } \\
\text { by Electronic Journal System }\end{array}$ \\
\hline \hline Task or Feature & $\begin{array}{c}\text { \% of Yes or } \\
\text { Maybe Responses }\end{array}$ \\
\hline Adequate type fonts, text & \\
design, and layout & $91.9 \%$ \\
Browsing text & 90.6 \\
Browsing graphics & 85.3 \\
Capability of underlining & \\
and annotating & 84.8 \\
Flipping pages and scanning & 82.9 \\
Portability of the text & 80.6 \\
Physical comfort & 78.4 \\
Experiencing serendipity & 73.7 \\
Creation of a print copy & 56.3 \\
\hline
\end{tabular}

An advantage of print is that I can use my finger to mark my place if I'm interrupted while reading. . . . With print, I feel that I'm more in "reading mode" whereas computer monitors are more like TV screens. I feel more passive; it's harder to read and pay attention.

It makes you feel connected. Otherwise, the article goes away when you turn the machine off.

It invokes the tradition and culture of the book, and I'm not comfortable interacting with the screen. The feel and the color of the print are important.

However, most negative responses emphasized greater interest in the content of an article than in the reading process. Because most respondents considered physical contact with the article and wide visual overview "not important," these have not been included in the discussion below.

\section{Satisfaction of Requirements by Electronic Journals}

For each task or feature, users were asked if they felt that electronic journals, in CORE or any other system, could fill that need as adequately as print journals. (Table 2 lists the percentage of respondents answering yes or maybe for each task.)

At least 84 percent or more of the respondents considered electronic journals capable of satisfying the need for adequate type fonts, browsing text and graphics, and underlining and annotating. Slightly fewer respondents thought that electronic systems, with substantial modifications, could evolve so as to provide adequate flipping and scanning abilities, and portability. Physical comfort and experiencing serendipity were more problematic, and almost half the respondents would still create a print copy of

Adequate type fonts, text design, and layout were generally considered within reach of electronic journals. The possibility of personalizing the interface also was mentioned. Indeed, Peat Marwick accountants tested by Brewster Kahle et al. ${ }^{14}$ wanted the ability to change the style or font themselves.

Users felt that electronic journals could support the need for browsing text by providing speed, currency, and comprehensiveness of coverage. articles they considered important. 
The notion of browsing graphics electronically was attractive:

Chemists are lucky; they have a system of drawing which is standardized. The minimum requirement would be to be able to draw a picture, via something like ChemIntosh, and search for it. The best would be to draw two structures and a transformation from one to the other and be able to search for that.

Users felt that electronic systems could provide annotating capabilities: to highlight text, cut and paste, insert notes, and even draw. Users provided a wealth of suggestions for facilitating flipping pages and scanning.

It would be useful to have a map showing where you are in the article-a square box with cells showing where you are.... You could click on the map to get where you want.

If I could view two pages at a time, because we are used to physical page turning.

I envision the following, which I would call a "blank book": if they could make screens thin and the same size as pages, maybe out of liquid crystal, and manufactured a book of ten or so of these blank pages, you could then plug in a journal article and then flip through.

You could do something like "eye tracking," which is used in systems for paralysis victims. Laser-oriented ... tracks the eye's motions and performs certain tasks like turn pages when a certain area was looked at.

However, others felt that flipping "pages" electronically is too slow.
Many users felt that they could satisfy the need for portability of the text with electronic journals. A few (not included in the percentages in table 2), specified that they would make printed copies, which would then be portable. Others mentioned using a small workstation, being able to access the system from many locations, and saving articles to disk to be used in a variety of locations. Others were less satisfied:

I want to be able to be reading while doing something else at the same time. For example, watching over a lab experiment.

Laptops ... would be awkward to hold.

Almost half the users found that using the CORE system was as comfortable as using print:

When you read in the library, you have to sit in one place, strain your eyes the same.

The degree of comfort for CORE journal use was the same as for any other format. I would still have to get up to move around or get a glass of water.

Another quarter of the users could imagine the potential for physical comfort in reading electronic journals:

It might help to be able to look down at a screen. That is a more natural reading position.

[If it were] relatively the same size as paper. An interface that is more convenient than a mouse and keyboard, like a light pen.

However, a full quarter of users still felt that electronic journals would never be as comfortable to read as printed jour- 
nals, mentioning eyestrain and lack of physical mobility while reading.

The notion of experiencing serendipity while using an electronic system elicited diverse responses. Ten users mentioned the search capability, a quality that distinguishes electronic systems from print, as an aid to serendipity:

Even though you don't have the physical volumes next to each other the way you would in the stacks, you can get a collection of articles together that you can look at. If I type in "Kramer," I will get not only the articles written by Kramer but also the articles that cite Kramer. That can be an important association.

\section{Interviewers deliberately phrased the question to ask whether elec- tronic journals can ever replace the need for printed copies. Almost half the respondents answered nega- tively, ...}

In contrast, some respondents considered the search capability a limitation because it retrieves only what is requested.

Other users mentioned different concerns:

It seems to depend on how free you can let your imagination be, and print just seems better for that.

There is a level of abstraction [with the computer] that interferes with my understanding of [the content]. Moving the mouse to highlight something breaks the concentration.

In discussing creation of a print copy, because obviously electronic journals can be created that produce printed copy, the interviewers deliberately phrased the question to ask whether electronic journals can ever replace the need for printed copies. Almost half the respondents answered negatively, citing the lack of portability, the need for permanence or a physical record, the need to make transparencies or handouts, and the lack of physical comfort:
No.... When I'm writing a paper, I browse through lots of things and like to have the papers arranged on my desk. On the screen ... I I can have only one or two papers open.
No. ... You can scan more articles faster [with electronic journals], but the only way to read them is to print them.

These results resemble those of other studies, where large numbers of users prefer printed copies. Describing the ADONIS system, Richardson commented, "None of the users appeared to have read articles on screen instead of printing copies." 15

Schauder's survey of more than 700 academics from Australia, the United Kingdom, and the United States found that 75 percent would prefer to read articles as printouts (assuming laser-quality printing) than on screen. ${ }^{16}$

In general, comments from CORE participants agreed with interviews by Ann Bishop of eighteen engineering faculty members and students. ${ }^{17}$ The engineers needed the ability to search and display sections of articles, jump to cited links, customize interface features, retrieve and skim figures, download and manipulate (e.g., annotate) retrieved material, and experience serendipity.

\section{Substitution of Print Journals by Electronic Journals}

Participants were asked whether electronic journals could be used for all scholarly journal reading. (Their answers are presented in table 3.) Negative responses were problematic. Although users were directed to consider all possible electronic 
journal systems, and not just CORE, several cited CORE's insufficient updating or journal coverage, demonstrating that they were not considering the entire range of systems. In table 3 , the negative responses are separated into two categories, depending on whether the reasons given were specific to CORE rather than to electronic systems in general. Nevertheless, more than half the respondents thought that electronic journals could possibly be used for

\begin{tabular}{|lc|}
\hline \multicolumn{2}{|c|}{ TABLE 3 } \\
\begin{tabular}{|l} 
Belief That Electronic Journals Could Be \\
Used for All Scholarly Journal Reading
\end{tabular} \\
\hline \hline Response & \% of Responses \\
\hline Yes & $41.0 \%$ \\
Maybe & 12.8 \\
No, for reasons & \\
$\quad$ specific to CORE & 12.8 \\
No & 30.8 \\
Answer unclear & 2.6 \\
\hline
\end{tabular}
all scholarly journal reading, whereas almost one-third disagreed. Most positive responses stressed that such a system must be updated frequently and cover all the needed journals, and that the user must have convenient access to a terminal.

The reasons for a negative response resembled those for needing a print copy: a need for permanence, portability, and ease of reading; and the instability of electronic information. One professor cited:

... the risks involved in losing what's there. Systems go out of style and the longevity of electronic formats is dubious. Electronic information has a poor track record in this regard.

To check consistency of responses, users were asked how many ACS journals they subscribed to personally and whether they would drop these subscriptions if the journals were made available electronically on a permanent basis. However, only sixteen respondents subscribed to any ACS journals, and only two subscribed to more than two. These low numbers may be due to the student status of many of the interviewees. In Olsen's 1992 study, chemists subscribed to an average of five journals each, many of which were probably ACS journals. ${ }^{18}$

Of the sixteen subscribers here, four would discontinue their print subscriptions and eleven would not. (One person

was unsure.) Three users who would not change commented that they disliked reading articles from a screen. Other comments were:

It is more convenient to reach for the paper copy on my shelf than to open the system, wait, etc.

I want a personal library of journals central to my work.

Interestingly, three nonsubscribers volunteered that an electronic system might encourage them to subscribe to more journals because of increased familiarity with them.

The idea that print journal use might remain constant, or even increase, when the same journals are available electronically was supported by preliminary data from the TULIP project, as described by Katherine Willis et al. ${ }^{19}$ During the academic quarter following the availability of various Elsevier/Pergamon journals online, use of the unbound paper issues of these journals rose more than 18 percent.

\section{Selected Characteristics of an Ideal System}

Users described their preferences in the areas of dates of coverage and presentation of graphics and text.

\section{Dates of Coverage}

Three questions were posed concerning dates of coverage: the frequency of up- 
dating necessary for readers to keep current, the number of past years needed for readers gathering background on a topic, and the number of past years available for locating specific articles or facts. Questions were open-ended; standard dates or intervals were not suggested. Listed in table 4 for each question are the median, the range and the most common responses.

David Everett, in his study on using existing online journals to fill documentdelivery requests at Stetson University, cited problems of insufficient periodical coverage and missing backfiles for many periodical titles. ${ }^{20}$ In this study, most scholars desired backfiles covering thirty, or even fifty years, with updates every two weeks or less. However, some rejected older information. Others claimed that the answer depended on the area of study.

\section{Presentation of Graphics}

Users were asked if they needed exact page images of graphics or whether extracted graphics (available in one of the CORE interfaces) were adequate. The wording of this question inadvertently confused two issues: exact versus nonexact images, and proximity of the graphic to its context. However, because respondents were encouraged to explain their answers, it was possible in many cases to determine which issue influenced the response. (See table 5.)

The majority of users felt that extracted graphics were adequate or preferred; however, a significant number felt the need for context-text and graphics presented in close proximity. This contrasts with Andrea Keyhani's findings from the design phase of the GUIDON interface. ${ }^{21}$ Her medical researchers preferred to view graphics in separate windows from the text.

\section{Presentation of Text}

Participants were asked whether they preferred exact page images or machinereadable text for textual material.

Users preferring exact page images (35.1\%) slightly outnumbered those preferring machine-readable text $(29.7 \%)$ and those with no preference (24.3\%). Other preferences were for both options or were unclear $(10.8 \%)$. Few reasons were cited for needing exact page images. Perhaps users believed, with Ann Schaffner, that:

The structure of documents serves to orient readers; readers must be able to move from one section of article to another easily, and they must be able to locate and reread sections efficiently. ${ }^{22}$

\begin{tabular}{|c|c|c|c|}
\hline \multicolumn{4}{|c|}{$\begin{array}{l}\text { TABLE } 4 \\
\text { Desired Dates of Coverage for an Electronic System }\end{array}$} \\
\hline Question & Median & Range & Most Common Response \\
\hline Frequency of updates & Every 2 Weeks & $\begin{array}{l}\text { From } 2 \text { days } \\
\text { before the print } \\
\text { journal to once } \\
\text { per year }\end{array}$ & $\begin{array}{l}\text { "As often as print," } \\
\text { "Monthly" }\end{array}$ \\
\hline $\begin{array}{l}\text { Backfiles needed for } \\
\text { background research }\end{array}$ & $20-30$ years & $\begin{array}{l}2 \text { years to the } \\
\text { same as print }\end{array}$ & "The same as print" \\
\hline $\begin{array}{l}\text { Backfiles needed for } \\
\text { locating specific } \\
\text { articles or facts }\end{array}$ & $\begin{array}{l}\text { Mid- } 1960 \text { s, or } \\
30 \text { years }\end{array}$ & $\begin{array}{l}\text { Several years } \\
\text { to the beginning } \\
\text { of each journal's } \\
\text { existence }\end{array}$ & $40-50$ years \\
\hline
\end{tabular}


Reasons cited for preferring machinereadable text included the ability to manipulate text, search for words within text, and move text.

Schauder, in his survey of more than 700 academics in Australia, the U. K., and the U. S., asked a similar question. ${ }^{23}$ Retaining the presentation style of the original article (defined as same typography and layout) was considered "necessary" by 17 percent and "desirable" by 56 percent, compared to the preference for exact page images by only 35.1 percent in the present study. However, his question did not suggest the alternative of machine-readable text.

Related to the need for exact page images is the desire for reproduction of the familiar journal format. Participants were not asked to comment directly on this question, and outside opinions and studies vary. Schaffner ${ }^{24}$ hypothesized that:

The grouping of articles into discrete journal titles with distinctive identities, and the format of individual articles, add structure and meaning to the body of scientific knowledge in subtle ways that are not yet thoroughly understood.

However, in Schauder's study, a question on the importance of reading an article as part of an entire journal issue, as opposed to an individual photocopy or reprint, elicited the response of "not important" from 54 percent of the participants. ${ }^{25}$

\section{Increased Productivity}

Users were asked whether they would read a greater number of complete articles using an electronic system than they read previously and whether they would read articles sooner.
More than half the respondents $(52.6 \%)$ said they would read more complete articles using an electronic system. The same number of articles or fewer would be read by 34.2 percent; other answers were unclear. Reasons for reading more articles included retrieving articles un-

\section{TABLE 5}

Graphics: Preference for Exact Page Images Versus Extracted Graphics

$\%$ of Responses

$43.2 \%$

27.0

13.5

available in the library and devoting the time to reading that formerly was spent searching. By contrast, one respondent would read fewer complete articles, but would browse more.

The majority of users $(60.5 \%)$ felt they would read articles earlier using an electronic system, with 26.3 percent experiencing no change and 13.2 percent being unsure or giving a mixed response. Positive responses mentioned reasons of convenience:

I'm more of a night person and the libraries are not open that late. I like to be able to read at 2:30 a.m. Late at night, there are fewer distractions- everybody's asleep, there are no classes, the restaurants are all closed, there are no sports going on.

There are fifteen people sharing one journal in my lab... with a computer system, everyone has one.

One negative response stressed:

I generally read articles when I can find the time. 


\section{Conclusions}

Research on a rapidly changing field such as electronic information produces a snapshot of only one moment in time. Interviews such as these provide a glimpse into the state of mind of potential users of electronic systems. The result is a product of the interaction between the state of the art of the products themselves, the current work habits of researchers, and their technological sophistication. The following conclusions can be drawn from these interviews:

- Of all the capabilities examined here, the abilities to create a printed copy and to browse both text and graphics were most important.

- Users anticipated that most functions of a journal system could eventually be accomplished by electronic journals. However, a significant group of users was pessimistic about their ability to experience serendipity, read comfortably, and forego printed copies.

- About one-third of users did not anticipate ever replacing print journals entirely.

- The number of personal print subscriptions would not immediately be affected by access to electronic journals.

- For most users, systems should be updated at least biweekly and include back issues covering the past forty to fifty years.

- Extracted graphics were adequate for most users, especially if they could also be viewed in context.

- Users were slow to see the advantages of machine-readable text.

- As a result of access to electronic journals, users expect to read more complete articles, spend their reading time more efficiently, and read articles sooner after publication.

\section{As Schaffner commented:}

Electronic journals must, at the start, at least serve the basic functions that print journals have traditionally served. Once the transition has been made, new technologies may allow us to add new roles, to drop some of the traditional roles, or to fill them in intrinsically different ways. ${ }^{26}$

Andrew Dillon's 1988 paper enumerates some of the possible enhancements: improved navigational capabilities, rapid browsing facilities, and customized printing. ${ }^{27}$ Another enhancement, full-text searching, which was not addressed in detail in the CORE survey, already exists. The results of the present survey indicate that with greater experience using electronic systems, chemists as a group are fairly optimistic about their potential. However, systems designers must still be concerned with improving the areas of portability, comfort, convenient access, permanence, and serendipity if electronic journals are to gain acceptance as a replacement for print. Users still need to read comfortably from diverse locations, feel confident that online information will not "disappear," and make the chance connections with literature that spark creativity. In addition to meeting these exacting use requirements, electronic journal producers face significant challenges outside this paper's scope in the areas of pricing, intellectual property rights, and conversion of a critical mass of information to electronic form. Despite the difficulties faced by database producers and system designers, the CORE user study indicates a likelihood of user acceptance if these challenges can be overcome. 
2. F. W. Lancaster, "Attitudes in Academia toward Feasibility and Desirability of Networked Scholarly Publishing," Library Trends 43 (spring 1995): 741-52.

3. Don Schauder, "Electronic Publishing of Professional Articles: Attitudes of Academics and Implications for the Scholarly Communication Industry," Journal of the American Society for Information Science 45 (1994): 73-100.

4. Jan Olsen, Electronic Journal Literature: Implications for Scholars (Westport, Conn.: Mecklermedia, 1994).

5. Richard Entlich, "Electronic Chemistry Journals: Elemental Concerns," Serials Librarian 25 (1995): 111-23.

6. Richard Entlich, Lorrin Garson, Michael Lesk, Lorraine Normore, Jan Olsen, and Stuart Weibel, "Making a Digital Library: The Chemistry Online Retrieval Experiment," Communications of the ACM 38 (Apr. 1995): 54.

7. Michael E. Lesk, "Electronic Chemical Journals," Analytical Chemistry 66 (July 15, 1994): $747 \mathrm{~A}-55 \mathrm{~A}$.

8. Larry Krumenaker, "Virtual Libraries, Complete with Journals, Get Real," Science 260 (May 21, 1993): $1066-67$.

9. Stu Borman, "Advances in Electronic Publishing Herald Changes for Scientists," CEEN (June 14, 1993): 10-23.

10. Olsen, Electronic Journal Literature, 29-53.

11. John Richardson, "Library User Trials with a CD-ROM Database," Computers in Libraries (Apr. 1991): 28-34.

12. D. J. Pullinger, "Attitudes to Traditional Journal Procedures," Electronic Publishing Review 3 (1983): 213-22.

13. Annette Simpson, "Academic Journal Usage," British Journal of Academic Librarianship 3 (spring 1988): 25-36.

14. Brewster Kahle, Harry Morris, Jonathan Goldman, Thomas Erickson, and John Curran, "Interfaces for Distributed Systems of Information Servicers," Journal of the American Society for Information Science 44 (1993): 453-67.

15. Richardson, "Library User Trials with a CD-ROM Database," 31.

16. Schauder, "Electronic Publishing of Professional Articles," 91.

17. Ann Peterson Bishop, "Scholarly Journals on the Net: A Reader's Assessment," Library Trends 43 (spring 1995): 545-70.

18. Olsen, Electronic Journal Literature, 16.

19. Katherine Willis, Ken Alexander, William A. Gosling, Gregory R. Peters Jr., Robert Schwarzwalder, and Beth Forrest Warner, "TULIP-The University Licensing Program: Experiences at the University of Michigan," Serials Review 20 (fall 1994): 39-47.

20. David Everett, "Full-Text Online Databases and Document Delivery in an Academic Library: Too Little, Too Late?" Online 17 (Mar. 1993): 22-25.

21. Andrea Keyhani, "The Online Journal of Current Clinical Trials: An Innovation in Electronic Journal Publishing," Database 16 (Feb. 1993): 14-15, 17-20, 22-23.

22. Ann C. Schaffner, "The Future of Scientific Journals: Lessons from the Past," Information Technology and Libraries (Dec. 1994): 239--47.

23. Schauder, "Electronic Publishing of Professional Articles," 91.

24. Schaffner, "The Future of Scientific Journals," 245.

25. Schauder, "Electronic Publishing of Professional Articles," 90.

26. Schaffner, "The Future of Scientific Journals," 240.

27. Andrew Dillon, John Richardson, and Cliff McKnight, "Towards the Development of a Full-Text, Searchable Database: Implications from a Study of Journal Usage," British Journal of Academic Librarianship 3 (spring 1988): 37-48. 

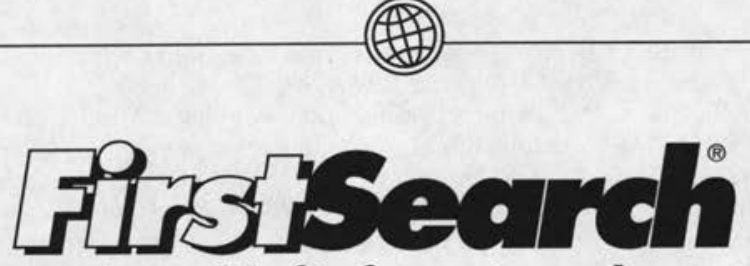

A world of information online

\section{THE FASTEST GROWING}

END-USER DATABASE SERVICE

\section{IN THE LIBRARY COMMUNITY}

- Full-text and images* Online

- Web Access

- NetFirst ${ }^{\mathrm{TM}}$ the authoritative guide to Internet resources

- WorldCat, ${ }^{\mathrm{TM}}$ the end-user version of the OCLC Online Union Catalog

- More than 50 databases

To find out how FirstSearch ${ }^{\circledR}$ can help you move to the next stage of the electronic library:

Call us at 1-800-848-5878, ext. 6425 to request a copy of .

the new FirstSearch brochure. Or view and order it online through our home page on the World Wide Web:

bttp://www.oclc.org

${ }^{*}$ Coming soon

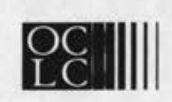

F URTHERING A CCESS TO THE W ORLD'S I NFORMATION 